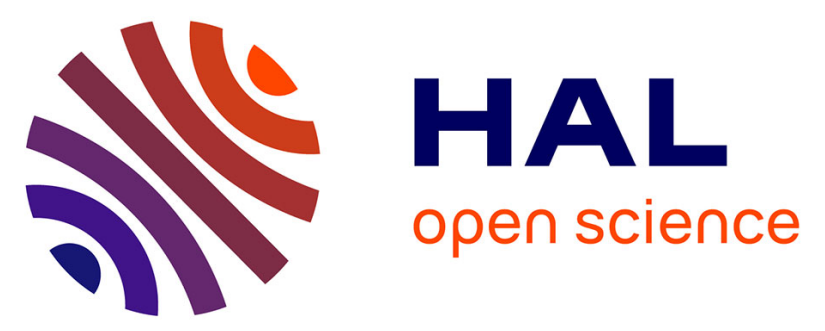

\title{
Influence of web/flange reinforcement on the GFRP bonded beams mechanical response: A comparison with experimental results and a numerical prediction
}

Marco Lamberti, Aurelien Maurel-Pantel, Francesco Ascione, Frédéric Lebon

\section{- To cite this version:}

Marco Lamberti, Aurelien Maurel-Pantel, Francesco Ascione, Frédéric Lebon. Influence of web/flange reinforcement on the GFRP bonded beams mechanical response: A comparison with experimental results and a numerical prediction. Composite Structures, 2016, 10.1016/j.compstruct.2016.03.043 . hal-01313883

\author{
HAL Id: hal-01313883 \\ https://hal.science/hal-01313883
}

Submitted on 23 Feb 2018

HAL is a multi-disciplinary open access archive for the deposit and dissemination of scientific research documents, whether they are published or not. The documents may come from teaching and research institutions in France or abroad, or from public or private research centers.
L'archive ouverte pluridisciplinaire $\mathbf{H A L}$, est destinée au dépôt et à la diffusion de documents scientifiques de niveau recherche, publiés ou non, émanant des établissements d'enseignement et de recherche français ou étrangers, des laboratoires publics ou privés. 


\title{
Influence of web/flange reinforcement on the GFRP bonded beams mechanical response: A comparison with experimental results and a numerical prediction
}

\author{
Marco Lamberti ${ }^{\mathrm{a}}$, Aurélien Maurel-Pantel ${ }^{\mathrm{b}}$, Francesco Ascione ${ }^{\mathrm{a}, *}$, Fréderic Lebon ${ }^{\mathrm{b}}$ \\ ${ }^{a}$ Department of Civil Engineering, University of Salerno, Via Giovanni Paolo II 132, 84084 Fisciano (SA), Italy \\ ${ }^{\mathrm{b}}$ LMA, Aix-Marseille University, CNRS, UPR 7051, Centrale Marseille, F-13402 Marseille Cedex 20, France
}

\begin{abstract}
This paper presents a wide numerical investigation about the influence of an external reinforcement of the web/flange connection on the performance of beams obtained by bonding simple panels to each other by means of epoxy resin.

Within this framework, two different models were developed: a 2D-model and a 3D-model. The 2D-model was used to understand the role played by the bonding joints in the experimental tests previously performed and to understand the influence of different types of reinforcements on the stress distribution in the adhesive layer. The 3D-model was implemented in order to study the influence of different web/flange reinforcements on the mechanical response of bonded beams and to predict their failure load and flexural stiffness.

The numerical results have shown how it is possible to obtain, for these new bonded beams, levels of performance higher than those of the current pultruded beams, allowing us to consider the bonding system proposed as highly competitive in the field of construction of pultruded profiles.
\end{abstract}

Keywords: Numerical analysis; Bonded interface; Glass Fiber Reinforced Polymer (GFRP) Flexural behavior; External web/flange reinforcement

\section{Introduction}

Fiber-Reinforced-Polymer (FRP) pultruded profiles initially were designed by the pultrusion industry and were taught for low-stress applications such as cooling towers, water and wastewater treatment plants. FRP pultruded beams take advantage of their principal features such as high stiffness and strength-toweight ratio, magnetic transparency, corrosion resistance, low thermal conductivity, absence of thermal bridges and an effective manufacturing process. Afterwards, since the late 1990s, FRP pultruded profiles reinforced with glass fibers (GFRP) have entered in the field of civil engineering as primary structural members, complementing other conventional materials such as steel, concrete, and wood in pedestrian and highway bridges, railway lines, and in the construction of full-composite structures [1-3].

Moreover, due to the fact that standard engineering guidelines developed for conventional materials are not applicable to FRP shapes, in the last few years several technical documents dealing with the design equations and methods, material properties, and safety factors for pultruded elements have been developed.

\footnotetext{
* Corresponding author.

E-mail address: fascione@unisa.it (F. Ascione).
}

In these documents, the pultruded elements could be considered as linear elastic, homogeneous, and transversely isotropic in the case of aligned fibers, with the plane of isotropy being normal to the longitudinal axis (i.e. the axis of pultrusion) [4-6].

On the other hand FRP profiles also present some less advantageous properties, such as relatively low elastic moduli, which often make design for serviceability and stability the governing limit states, hiding the advantage of the high strength of the fiber.

Nowadays it is possible to include many examples of fullcomposite structures realized by means of pultruded profiles. Among them the most famous are: the 5-storey GFRP Eyecatcher Building erected in Basel, Switzerland in 1998 for the Swiss Building Fair; the pedestrian Fiberline Bridge in Kolding, Denmark (open on 18 June, 1997 as the first composite bridge in Scandinavia); and the bridge over Deer Creek in Maryland State, USA, where the deck on a steel through-truss bridge was replaced by FRP composite deck. The weight of the new deck was about $40 \%$ less than a conventional concrete deck, resulting in increased live load capacity for the bridge.

In all these structures, pultruded profiles were joined together to form more complex cross-sections. For example, in the Fiberline bridge, the arches and the tied longitudinal bridge deck girders were made of a rectangular hollow FRP cross-section obtained 
from two U-profiles joined together with two bonded flat plates to form the rectangular tubular section.

As a consequence, these unconventional cross-sections represent a critical point relative to the mechanical response in terms of buckling, deformability, and adhesive layer resistance of such elements.

Although the bonding technique is nowadays a custom, relative to the bonding of pultruded plates and/or to the bonding of pultruded lamina to concrete, masonry and steel substrates [7-13], there is a lack of knowledge with respect to bonding together two pultruded profiles to form more complex shapes.

This lack of confidence has inspired the present research, conducted in collaboration with the Universities of Salerno and Aix Marseille, focusing on the study of a low-cost design strategy based on modularity. The final object of the research will consist on the possibility of achieving a GFRP profile with a complex crosssectional shape, not available on the market with a cost lower then pultrusion process, by bonding an appropriate number of simple pultruded plates with a common epoxy glue.

In order to do this, the first step was to compare the experimental results for a common profile (I - profile today available on the market) to a similar one obtained by this new technique.

From an economic point of view, the greater the number of beams to achieve the above technique is more advantageous than the pultrusion. The great saving is however intended in the realization of complex shapes, that with the technique of pultrusion would be economically feasible only in the case of large-scale production. The first results of a large experimental investigation [14], still under development by the authors, have shown the possibility of achieving a very good performance, in terms of both failure load and flexural stiffness when web-to-flange junctions were opportunely strengthened.

Only reinforcement with epoxy resin was taken into account. In order to continue the experimental campaign, regarding to the beams with the best web/flange reinforcement, it has been necessary to study previously by numerical point of view the influence of the web/flange reinforcement on the flexural behavior of bonded beams. For this task, Abaqus FE Code was used. Two different models were developed: a 2D-model and a 3D-model.

The 2D-model was used to study the stress distribution in the adhesive layer when different types of reinforcement geometry were used. This model is also used to choose the optimal numerical methodology to model the adhesive behavior as discussed in depth in Section 3.

The 3D-model was implemented in order to study the influence of such different reinforcements on the mechanical response of bonded beams in terms of failure load and flexural stiffness making a comparison with experimental results. The idea is to propose a predictive model in order to test numerically new sections or new reinforcement geometries as discussed in Section 4.

The main conclusion from the experimental and numerical first results is that it is possible to obtain, for these new bonded beams, levels of performance higher than those of the current pultruded beams, in terms of failure load and stiffness, allowing us to consider the bonding system proposed as highly competitive in the field of construction of pultruded profiles.

\section{Experimental tests: a brief summary}

The numerical analysis presented in this paper is based on the results of an experimental campaign conducted previously by the authors [14] and in this section briefly summarized. The experimental investigation consisted of four point bending tests performed on GFRP beams in order to study their flexural behavior. In particular, two kinds of beams were investigated:
- Type 1 (pultruded I-beams) entirely manufactured by the pultrusion process;

- Type 2 (bonded I-beams) obtained by bonding simple rectangular pultruded panels.

The pultruded I-beams were obtained entirely by the pultrusion process while bonded I-beams were created by bonding 3 simple pultruded panels. It is important to underline that the final shapes are essentially the same, except for the rounded webflange zones. The geometrical dimensions of both types of beam and mechanical properties, as declared by the producer, are reported in Table 1. A total of 4 pultruded I-beams and 6 bonded beams were investigated. Furthermore, 4 bonded I-beams were strengthened by adding an adhesive curb (Sikadur-30) at the web-flange junction on both the left and right sides, as shown in Fig. 1c.

The dimensions of the curb were $10 \mathrm{~mm} \times 10 \mathrm{~mm}$ over the full length of the beam $(1400 \mathrm{~mm})$.

The main results are that bonded beams exhibit an excellent performance compared to pultruded beams in terms of flexural stiffness, while no relevant difference can be observed in terms of failure load. Furthermore, the web-flange reinforcement plays a crucial rules as well as the curing temperature [14].

\section{2D model: the role played by the web/flange reinforcement in bonded beams}

One of the main results of the experimental investigation was the strong role played by the web/flange reinforcement with respect to the mechanical response of bonded beams. In particular, in order to study the influence of such reinforcement on the flexural behavior of bonded beams, a wide numerical simulation was performed using the Abaqus FE Code.

In details, the analysis was organized into three steps:

- The first step was devoted to finding the best finite element model for the adhesive layer (connection between web and flanges).

- In the second step a qualitative comparison, in terms of stress distribution in the adhesive layer, between different types of reinforcement varying the geometry was performed.

- In the last step, a qualitative comparison in terms of stress distribution in the adhesive layer, between different types of material reinforcement, was performed. In particular, both the adhesive layer and external reinforcements were assumed to be made of different epoxy resins available on the market.

Table 1

Type 1 and Type 2 beams: geometrical dimensions and mechanical properties.

\begin{tabular}{llll}
\hline Cross-section shape & $I$ & & \\
Geometrical dimensions & & Measure unit & Value \\
Flange panels width & $B$ & $\mathrm{~mm}$ & 100 \\
Web panels height & $h$ & $\mathrm{~mm}$ & 176 \\
Flange panels thickness & $t_{1}$ & $\mathrm{~mm}$ & 10 \\
Web panels thickness & $t_{2}$ & $\mathrm{~mm}$ & 10 \\
Radius & $R$ & $\mathrm{~mm}$ & 10 \\
Glue thickness & $t_{3}$ & $\mathrm{~mm}$ & 2 \\
Whole cross-section height & $H$ & $\mathrm{~mm}$ & 200 \\
Mechanical properties & & & \\
Young's modulus of elasticity & $E_{0^{\circ}}$ & $\mathrm{MPa}$ & 28,000 \\
Young's modulus of elasticity & $E_{90^{\circ}}$ & $\mathrm{MPa}$ & 8,500 \\
Shear modulus of elasticity & $G$ & $\mathrm{MPa}$ & 3,000 \\
Poisson's ratio & $v_{0^{\circ}, 90^{\circ}}$ & - & 0.23 \\
Poisson's ratio & $v_{0^{\circ}, 90^{\circ}}$ & - & 0.09
\end{tabular}

Pulling direction during pultrusion process (axis of pultrusion). 


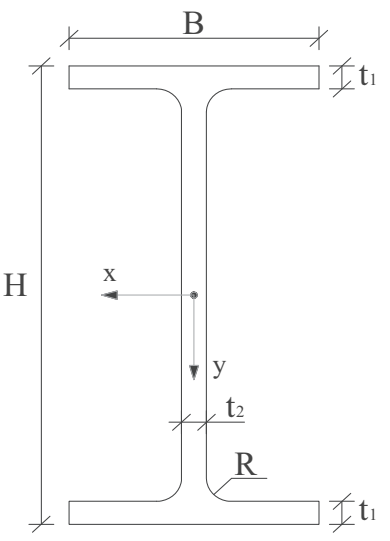

(a)

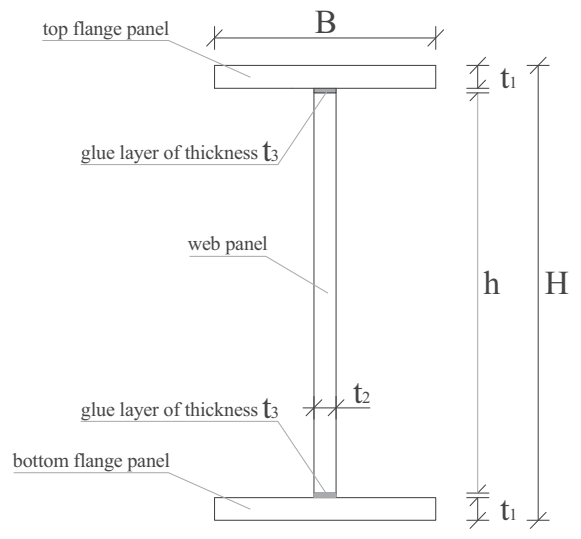

(b)

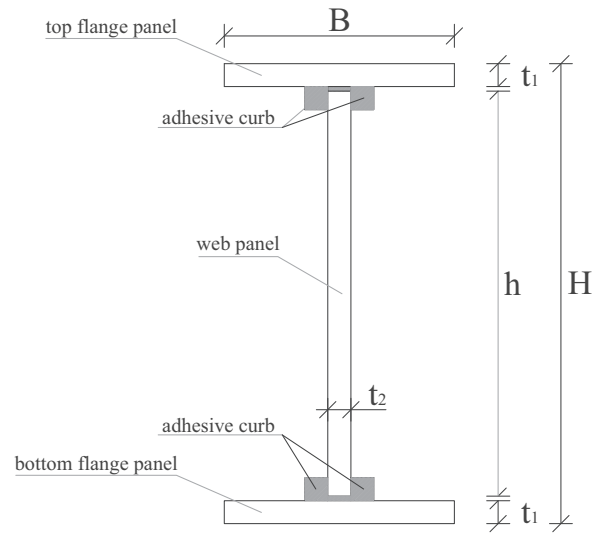

(c)

Fig. 1. Cross section shapes: (a) Type 1 beam; (b) Type 2 beam; (c) Type 2 beam strengthened.

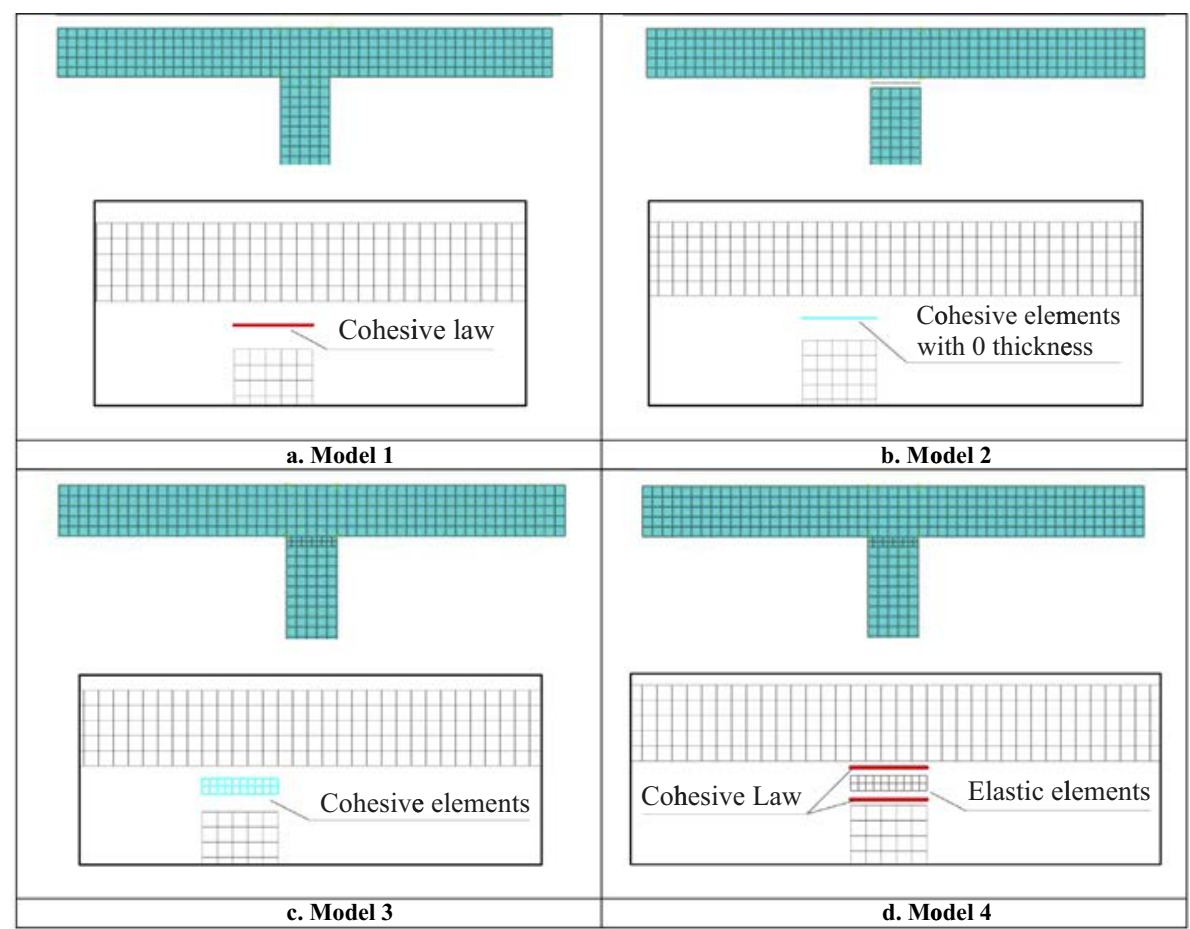

Fig. 2. Four different models to describe the adhesive layer behavior.

\subsection{Adhesive layer modeling - step 1}

In order to find the best way to model the adhesive layer, 4 different possible models were developed (Fig. 2a-d):

- Model 1: a contact cohesive constitutive law is implemented at the interface between the flange and the web;

- Model 2: 2D-cohesive elements with zero thickness are used, useful to model the crack propagation in glue material when it is very thin;

- Model 3: 2D-cohesive elements;

- Model 4: elastic 2D-elements bonded directly to the web and the flanges by means of a cohesive contact law.
In models 3 and 4 the total thickness of the adhesive layer is equal to $2 \mathrm{~mm}$, the same value adopted in the experimental campaign.

The four models introduced above are used to study the qualitative stress distribution along the adhesive layer for beam type 2 (bonded beams). The mechanical and geometrical properties were the same as those introduced in Table 1. An eccentric vertical displacement $u_{y}$, assumed equal to $3 \mathrm{~mm}$, is applied at the left end of the upper flange while the lower flange was fully fixed, as is shown in Fig. 3.

A CPS 4 - node bilinear - plane stress - quadrilateral element with length $2 \mathrm{~mm}$ was used for meshing the cross section of the beam while for meshing the adhesive layer the following meshes were adopted: 


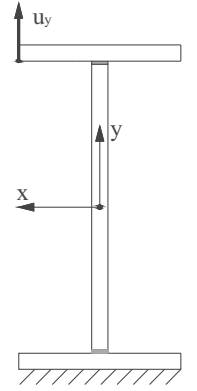

Fig. 3. Static scheme of the $2 \mathrm{D}$ model.

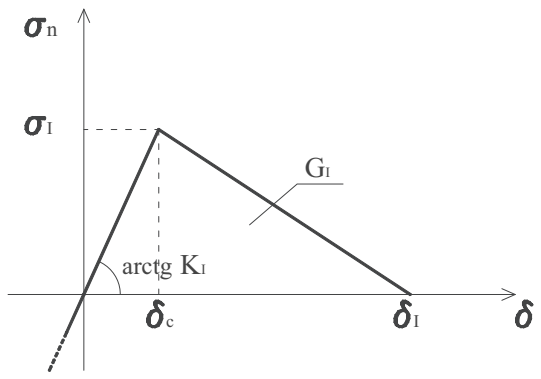

Fig. 4. Bilinear constitutive law in Mode I.

Table 2

Mesh details relative to models 2 and 3 .

\begin{tabular}{llllll}
\hline Mesh \# & Upper flange & Lower flange & Web & Adhesive & $s_{y}$ [MPa] \\
\hline 1 & 250 & 250 & 440 & 5 & 21.9444 \\
2 & 250 & 250 & 440 & 7 & 21.6850 \\
3 & 250 & 250 & 440 & 16 & 21.4675 \\
4 & 250 & 250 & 440 & 20 & 21.4025 \\
5 & 250 & 250 & 440 & 22 & 21.4009 \\
\hline
\end{tabular}

Table 3

Mesh details relative to model 4 .

\begin{tabular}{llllll}
\hline Mesh \# & Upper flange & Lower flange & Web & Adhesive & $s_{y}[\mathrm{MPa}]$ \\
\hline 1 & 250 & 250 & 440 & 5 & 20.7679 \\
2 & 250 & 250 & 440 & 7 & 20.6863 \\
3 & 250 & 250 & 440 & 16 & 20.6761 \\
4 & 250 & 250 & 440 & 20 & 20.6699 \\
5 & 250 & 250 & 440 & 22 & 20.6695 \\
\hline
\end{tabular}

- for what concern model 1 the adhesive layer was modeled by means of a cohesive law as depicted in Fig. 4;

- for what concerns models 2, 3 and 4 a mesh of twenty elements was adopted as described in details in Tables 2 and 3 and depicted in Fig. 2. The reference parameter utilized in the convergence test was the stress $s_{y}$ along the $y$ direction in the adhesive layer.

For what concerns the modelization aspects, more in details, in model 1 the cohesive law representing the damage between the flange and the web was characterized by an elastic linear branch followed by a softing linear branch as depicted in Fig. 4 relative to Mode I of fracture. By using symbols introduced in Fig. 4, the quantity $\sigma_{I}$ represents the interfacial tensile strength in the normal direction, the quantity $K_{I}$ represents the elastic stiffness of the interface, the quantity $\delta_{c}$ the displacement at the end of the linear
Table 4

Mechanical properties of the adhesive provided by the producer.

\begin{tabular}{llll}
\hline & & Unit & Value \\
\hline SikaDur30 & & & \\
Elastic stiffness & $K_{I}$ & $\mathrm{~N} / \mathrm{mm}$ & 10,400 \\
Tensile strength & $S_{I}$ & $\mathrm{MPa}$ & 31 \\
Fracture energy & $G_{I}$ & $\mathrm{~kJ} / \mathrm{m}^{2}$ & 3 \\
Adesilex Pg1 & & $\mathrm{N} / \mathrm{mm}$ & \\
Elastic stiffness & $K_{I}$ & $\mathrm{MPa}$ & 6,000 \\
Tensile strength & $S_{I}$ & $\mathrm{~kJ} / \mathrm{m}^{2}$ & 18 \\
Fracture energy & $G_{I}$ & & 1 \\
Kemiepox & & $\mathrm{N} / \mathrm{mm}^{2}$ & \\
Elastic stiffness & $K_{I}$ & $\mathrm{MPa}$ & 3,500 \\
Tensile strength & $S_{I}$ & $\mathrm{~kJ} / \mathrm{m}^{2}$ & 40 \\
Fracture energy & $G_{I}$ & & 1 \\
\hline
\end{tabular}

elastic branch while $\delta_{I}$ the displacement (separation) at failure. Finally, the quantity $G_{I}$ represents the total energy dissipated equal to the area subtended by the curve. The values adopted for the parameters before introduced are summarized in Table 4.

Furthermore, relative to model 2 a COH2D4 4-node-twodimensional-cohesive element was used.

The damage is represented by the increment of the thickness of the cohesive elements starting from zero value by adopting a damage evolution and a limit traction value relative to the adhesive.

Relative to model 3 the same elements as model 2 are used but they are characterized by a thickness. The damage is represented by the deformation of such elements considering the same traction limit value of the adhesive used in model 2 (Table 4).

Finally, in model 4 the adhesive layer was modeled by CPS 4 - node bilinear - plane stress - quadrilateral element as for the cross section, inserted into two cohesive laws of Fig. 4.

The results in term of stress $\sigma_{y}$ along the $y$ direction in the adhesive layer are depicted in Fig. $5 \mathrm{a}$ and $\mathrm{b}$ for all adhesive models considered. It is important to remark that the stress distribution is evaluated with respect to both the nodes belonging to the flange (Fig. 5a) and to the nodes belonging to the web (Fig. 5b).

Except the left edge where the displacement is applied no substantial differences emerged between the 4 models introduced. In conclusion the authors have been adopted in the next the model 1 for which the higher tensile stress was recorded.

\subsection{Web/flange reinforcement shapes: stress distribution in the adhesive layer - step 2}

The aim of this section consists in analyzing numerically the qualitative stress distribution in the adhesive layer for both two types of bonded beams tested experimentally [14] (Type 2 and Type $2 r$ of Section 2) in order to understand the role played by the reinforcements on the better mechanical response of the reinforced beam (Type 2r).

Subsequently, relative to reinforced bonded beams only (Type $2 r$ ), the influence of different reinforcement shapes on their flexural response is investigated.

It is important to remark that in the experimental campaign the external web/flange reinforcement was made by the same epoxy resin as that used for the adhesive layer. Then, the same assumption was made in the numerical analyses.

By adopting the 2D-model discussed in the previous section, a comparison between the behavior of Type 2 and Type $2 \mathrm{r}$ beams is performed. The geometrical and mechanical properties of these two beams are reported in Table 1 . The static scheme was the same as Section 3.1: the value of the eccentric displacement $u_{y}$ along the $y$ axis, applied at the left end of the upper flange was equal to $3 \mathrm{~mm}$; the lower flange is fully fixed (Fig. 3). 
(a)

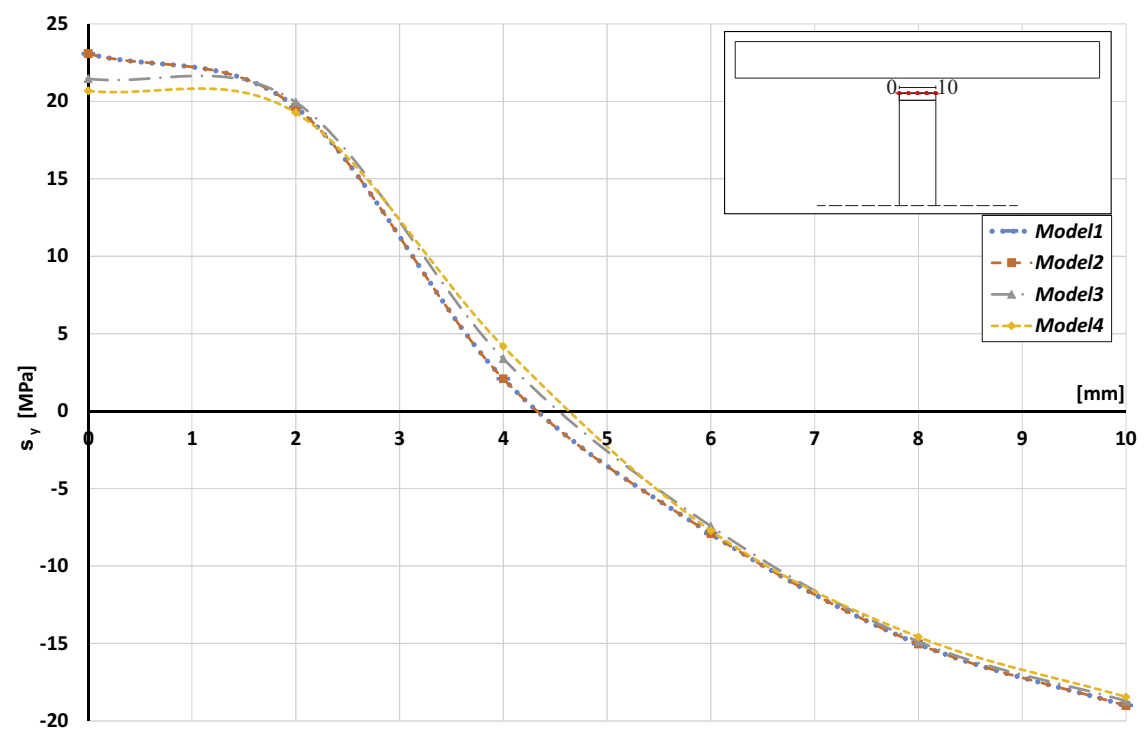

Fig. 5a. $\sigma_{y}$ stress distribution for the 4 models: nodes belonging to flange.

(b)

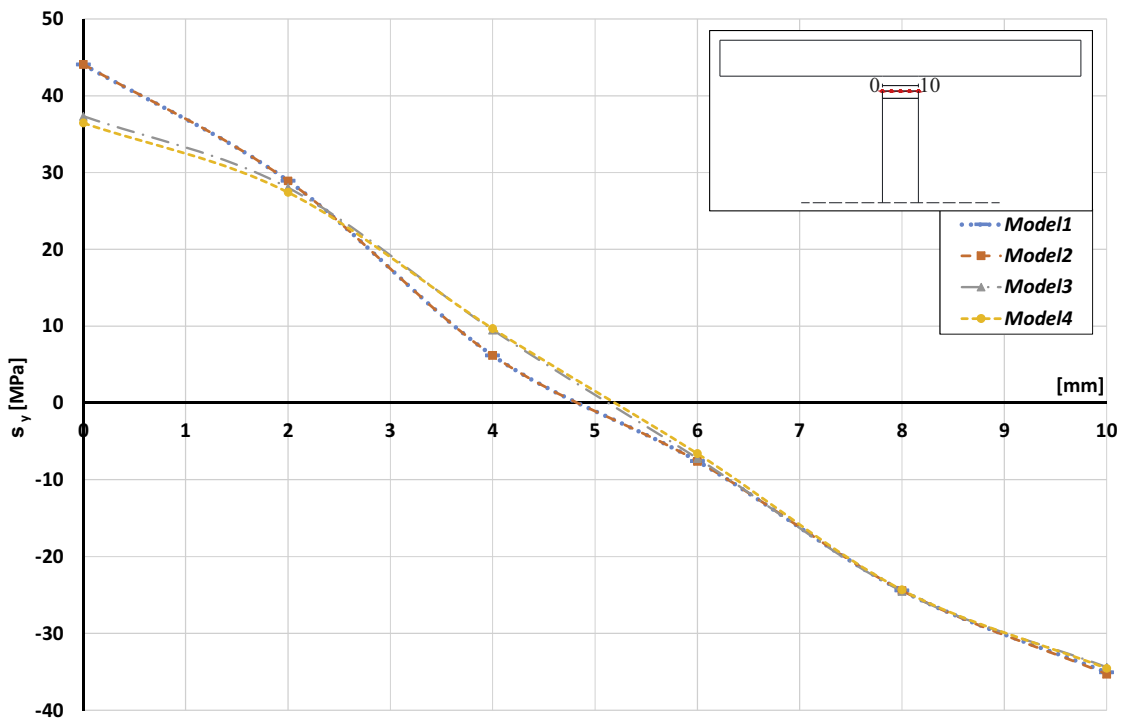

Fig. 5b. $\sigma_{y}$ stress distribution for the 4 models: nodes belonging to web.

The results, in terms of the stress distribution $s_{y}$ in the adhesive layer for both beams (Type 2 and Type 2r) are depicted in Fig. 6.

It is worth nothing that the presence of an adhesive square curb (Type $2 \mathrm{r}$ beam) leads to having a lower stress distribution than that of the Type 2 beam (i.e. absence of reinforcement) as experimentally evaluated (this means higher flexural rigidity of the beam). In particular, relative to Type $2 \mathrm{r}$ beam respect to Type 2 beam, the stress at the left edge of adhesive layer is three times smaller; the stress on the right edge of the adhesive layer is quite zero while the stress distribution along the entire adhesive layer assumes values between +8 and $-4 \mathrm{MPa}$.

The numerical analysis previously described and discussed is now extended to several reinforcement shapes taking into account as material both the epoxy resin SikaDur30 and GFRP. In particular, several shapes were considered: square, rectangle, triangle and pluri-rectangle, as depicted in Fig. 7. These reinforcements are bonded to the cross section by means of epoxy resin SikaDur30.

The results, in terms of the stress distribution $s_{y}$ along the horizontal contact line with upper flange are reported for all shapes reinforcement considered. In Figs. 8-11, the reinforcement shapes with minimum and maximum dimensions are depicted. Relative to the reinforcement with rectangle shape the minimum dimension was considered only depending on the major increment of the second moment of area $I_{x}$ respect to the maximum dimension. This last dimension has been considered in the $3 \mathrm{D}$ analysis as reported in the next.

The numerical results allow us to underline the following considerations: 


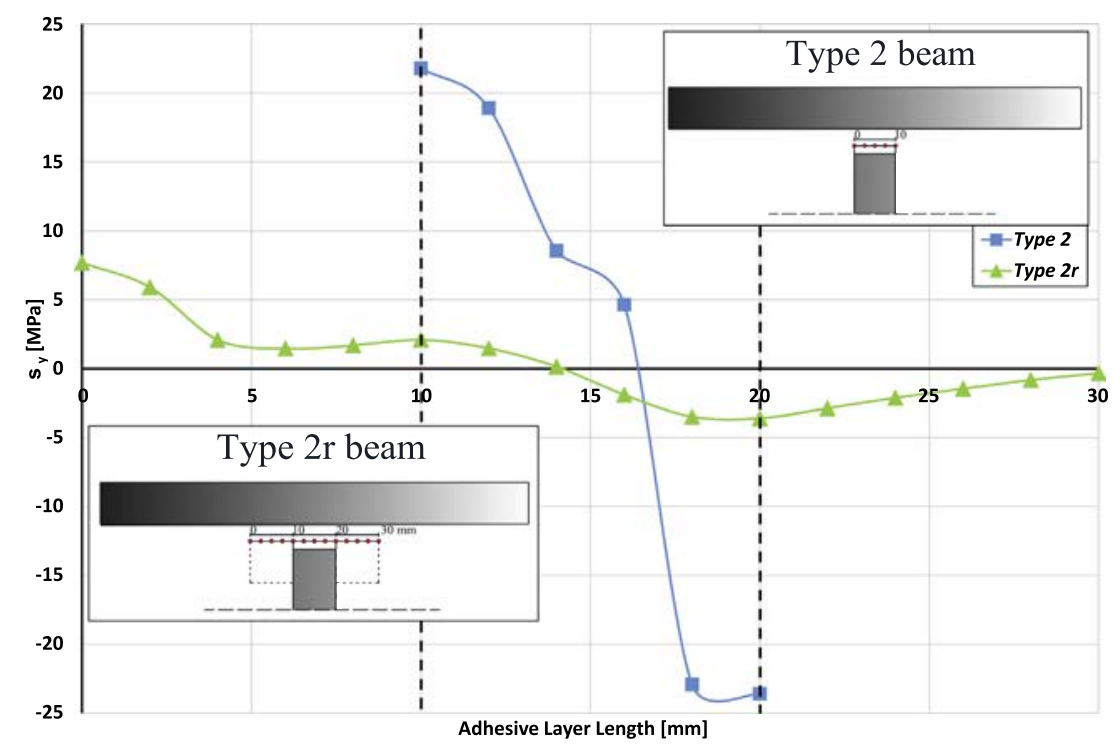

Fig. 6. Comparison between Type 2 and Type 2r.

(1) For a fixed reinforcement shape, the $s_{y}$ stress distribution decreases if GFRP material is considered except of the left edge of the flange close to the point of application of the displacement. As a consequence the web/flange connection strength increases, so an improvement of the bonded beam mechanical response is obtained.

(2) For a fixed reinforcement material, the $s_{y}$ stress distribution decreases if the second moment of area $I_{x}$ is increased. This means that the best choice is a reinforcement with the maximum length along the web of the cross section.

3.3. Web/flange reinforcement materials: stress distribution in the adhesive layer - step 3

In this section the numerical analysis conducted previously has been extended to the cases where the reinforcement and the adhesive layer were made of different epoxy resins. In particular

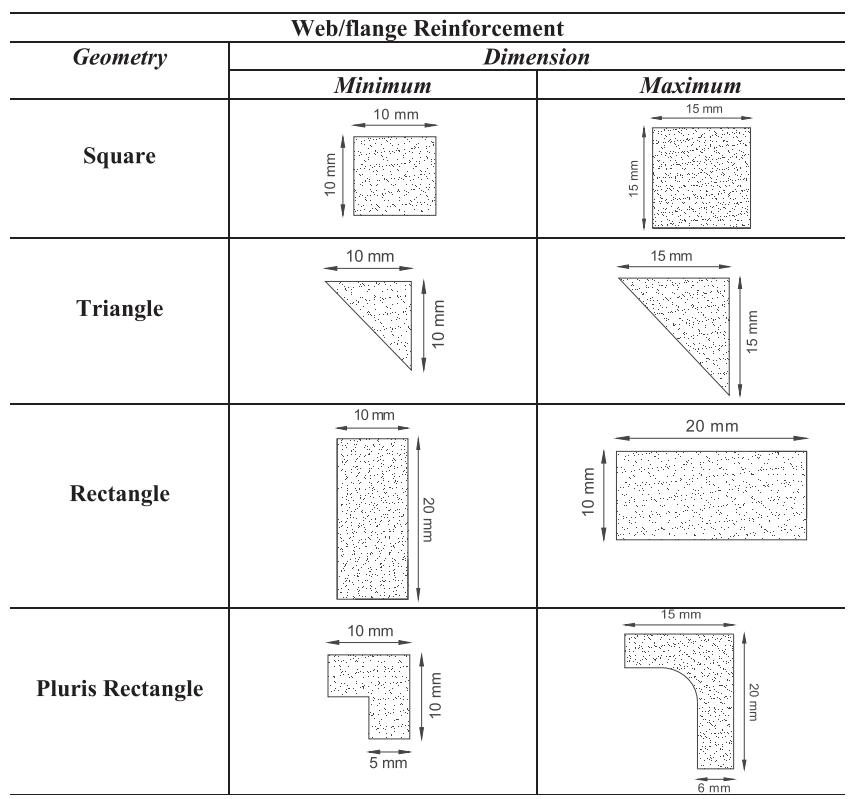

Fig. 7. Web/flange reinforcement shapes.
SikaDur30, Adesilex Pg1 and Kemiepox are considered. The mechanical properties of the adhesives are reported in Table 4 where symbols are those introduced in Fig. 4.

Here the square shape for the reinforcement is only considered. Furthermore, the case in which the reinforcement is in GFRP and adhesive layer is made of different epoxy resins is also studied. The results in terms of $s_{y}$ stress distributions along the adhesive layer are reported in Figs. 12 and 13.

The numerical results allow us to underline the following considerations:

(1) The $s_{y}$ stress distribution decreases when reinforcement material is GFRP and not epoxy resin except of the left edge of adhesive layer near the point of the displacement applied;

(2) Considering external reinforcement in GFRP, the $s_{y}$ stress distribution decreases when SikaDur30 epoxy resin is used to bond it to the cross section except for the left edge of the adhesive layer.

\section{3D model: the influence of the web/flange reinforcement on the mechanical response of bonded beams}

In this section a 3D-model in the FE Abaqus Code is performed in order to study the influence of different web/flange reinforcements on the mechanical response of bonded beams in terms of failure load and flexural stiffness. In particular, all reinforcement shapes of the 2D analysis were considered.

In order to predict the failure load as well as the flexural displacements evaluated in the experimental campaign, the fourpoint bending test was simulated by adopting a 3D-model in Abaqus.

Thanks to the two axes of symmetry $(x, y$ and $y, z)$ depicted in Fig. 14, only a quarter of beam is simulated, reducing computation time and memory.

The aforementioned symmetries were implemented by inhibiting the displacements, $u$, orthogonal to the symmetry planes as follows:

- relative to plane $\{x, y\}$ the displacements $u(x)$ and $u(z)$ assume zero value;

- relative to plane $\{y, z\}$ the displacement $u(x)$ assumes zero value. 


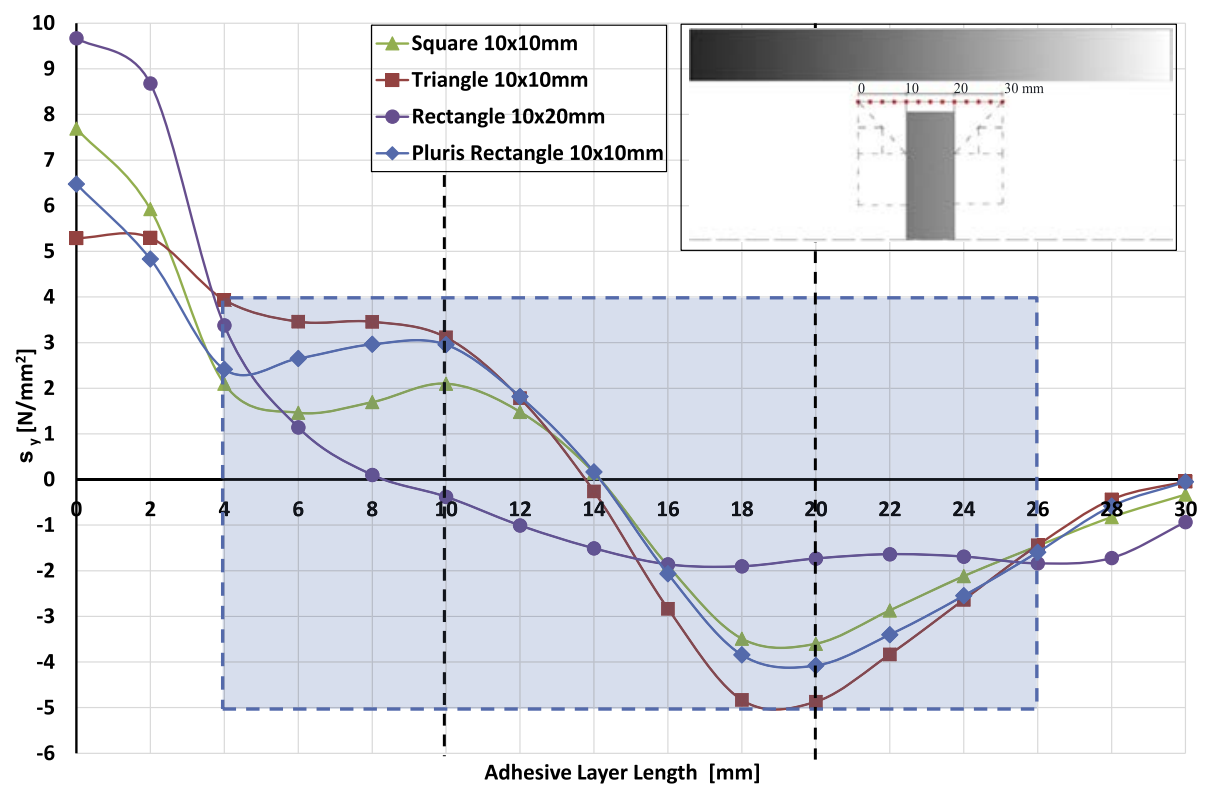

Fig. 8. Stress distribution $s_{y}$ along the contact line between reinforcement and upper flange for different shapes reinforcement made of SikaDur30 (minimum values).

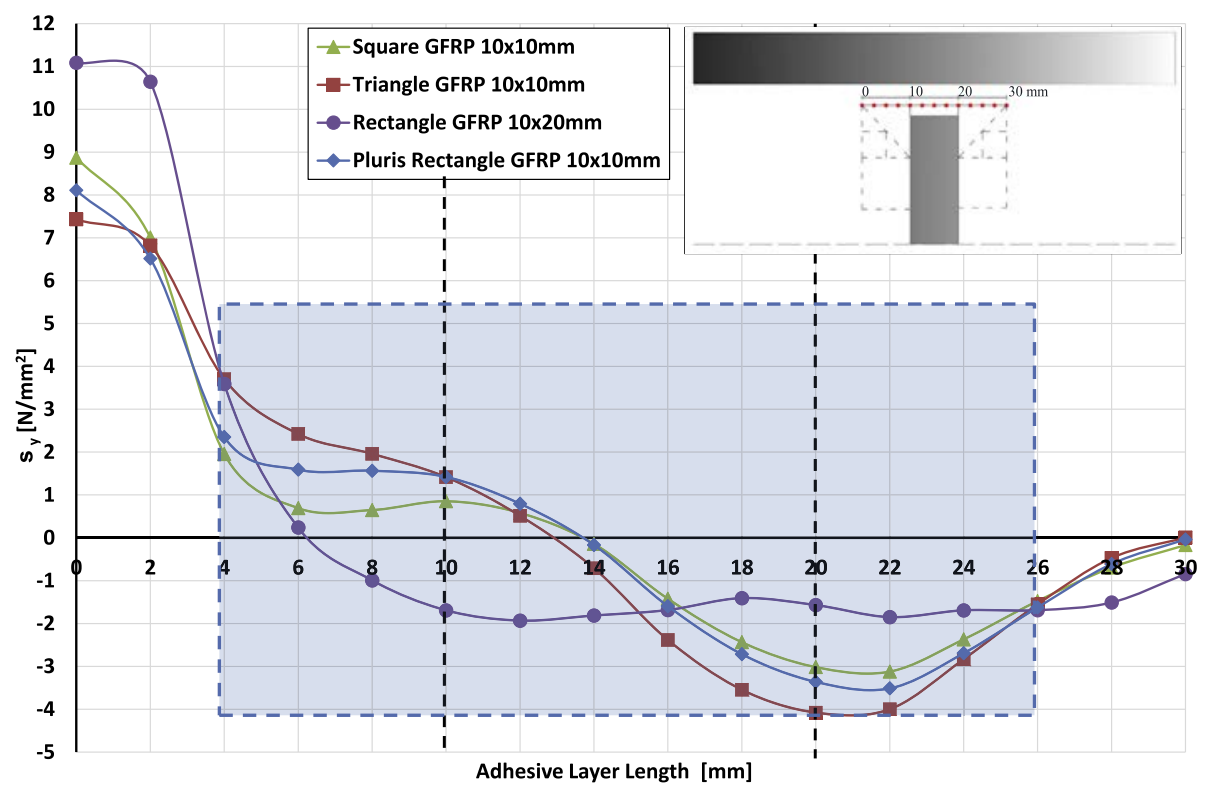

Fig. 9. Stress distribution $s_{y}$ along the contact line between reinforcement and upper flange for different shapes reinforcement made of GFRP (minimum values).

C3D 8-node linear brick elements with a length equal to $2.5 \mathrm{~mm}$ are used for meshing the quarter of the beam (Fig. 15). The mesh details are reported in Table 5.

Furthermore, the mesh adopted for any type of reinforcement considered is reported in Table 6.

To simulate the adhesive layer the cohesive law introduced in Section 3 was used.

The damage occurs only in the adhesive layer and its evolution is governed by energy in Mode I $\left(G_{I}\right)$ dissipated.

Finally, due to the symmetry a quarter of the active vertical force is applied on the quarter of beam.

Considering the symmetries conditions before introduced the external force, $F_{m}$, applied in $y$ direction on the model
(Fig. 14), correspond to a total force $F$, acting on the structure $\left(F=4 F_{m}\right)$

In order to verify the accuracy of the present model, a comparison with the experimental results is performed. In particular, numerical results were compared to experimental ones [14] relative to the four-point bending test of Type 2 beam (T2_6 test) and Type 2r beam (T2r_5 test) as depicted in Figs. 16 and 17, respectively. It is important to underline that the experimental results considered are relative to beams with a curing temperature equal to $28^{\circ} \mathrm{C}$.

As it is possible to verify from the load-displacements graphs, the numerical results are in good agreement with experimental data for what concern the reinforced beams highlighting the 


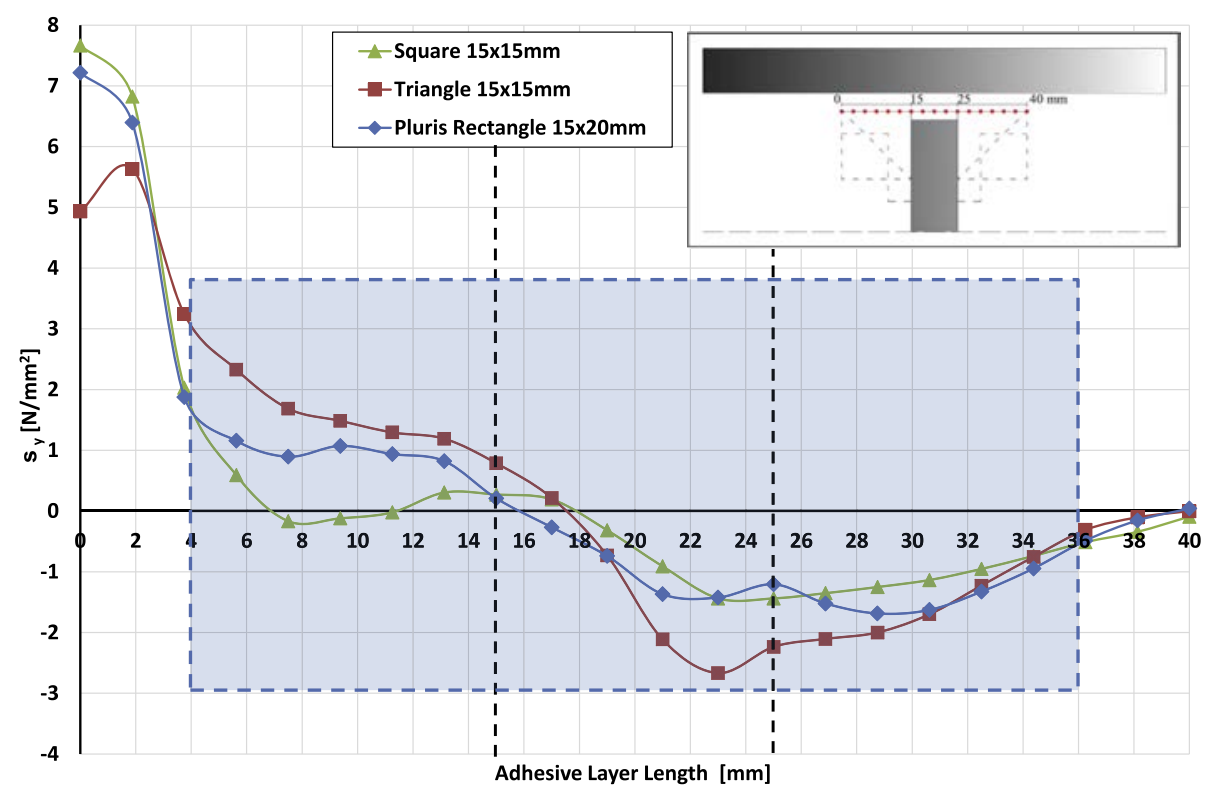

Fig. 10. Stress distribution $s_{y}$ along the contact line between reinforcement and upper flange for different shapes reinforcement made of Sikadur30 (maximum values).

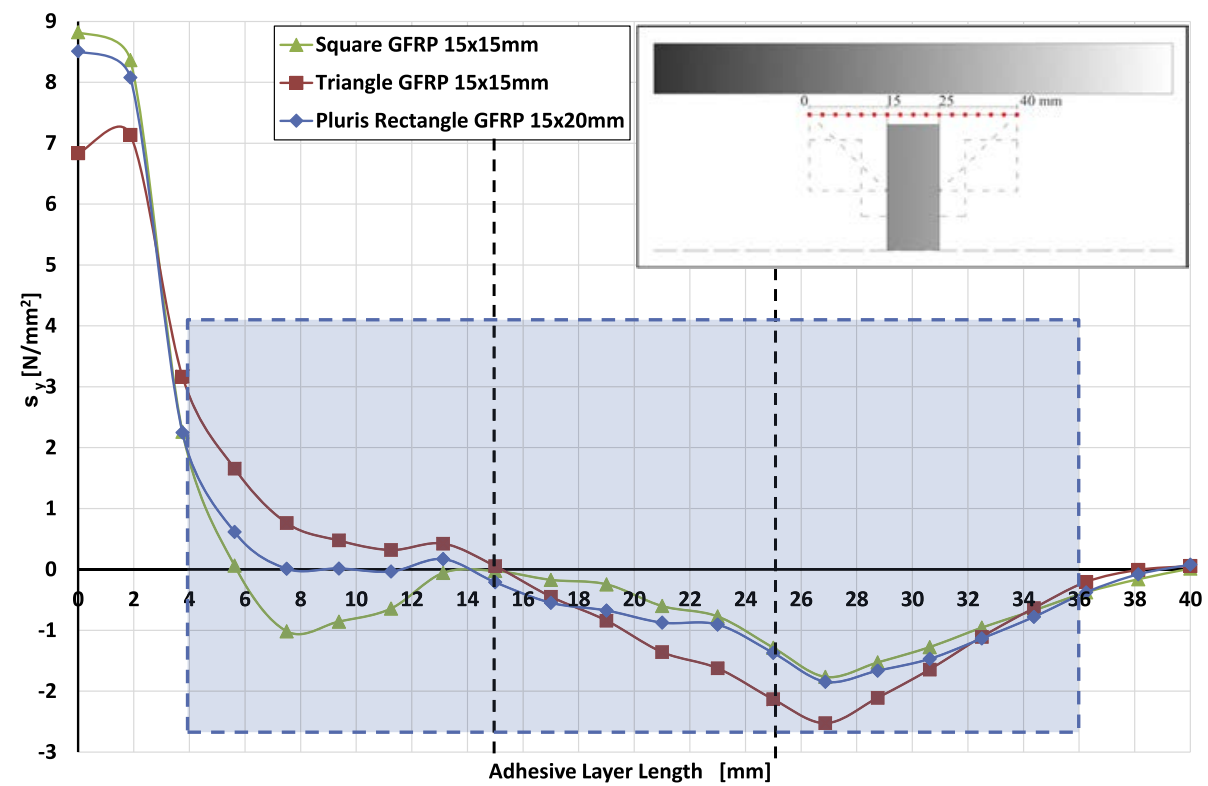

Fig. 11. Stress distribution $s_{y}$ along the contact line between reinforcement and upper flange for different shapes reinforcement made of GFRP (maximum values).

non-linear behavior and the loss of stiffness when the load increases as experimentally shown.

The numerical evaluation of the load peak value is obtained when the total fracture energy $G_{I}$ is dissipated (equal to the area subtended by the curve in Fig. 4).

In particular, with respect to bonded beams without reinforcement (Fig. 16), the predictive analysis is in good agreement with experimental results for what concerns failure load; and it is less conservative with respect to the deformability. Furthermore, with respect to bonded beams with reinforcement, the predictive analysis is in perfect agreement with the T2r_5 beam experimental results both in terms of failure load and deformability.

\subsection{Predictive analysis}

Based on 3D-model presented in the previous section a numerical analysis is developed in order to predict the failure load and flexural strains relative to bonded beams varying the geometry and mechanical properties of the web/flange reinforcement.

In particular, the reinforcement was made of both SikaDur30 (SD30) epoxy resin and GFRP.

The numerical results are presented in Figs. 18-21 where load-vertical displacement curves are depicted.

The results in terms of failure loads and vertical flexural displacement are also summarized in Table 7. In particular, the second moment of area $I_{x}$ for each bonded beams is evaluated by scaling 


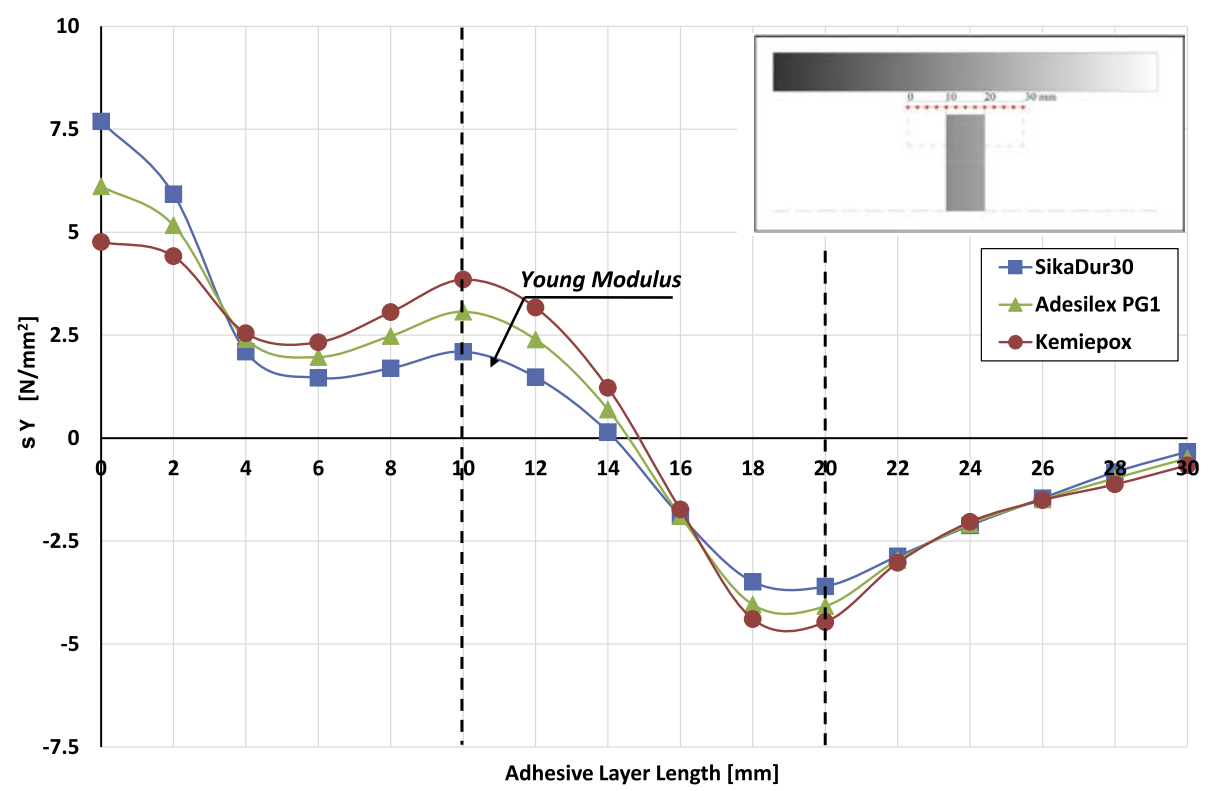

Fig. 12. Stress distribution $s_{y}$ relative to square reinforcement made of different epoxy resins.

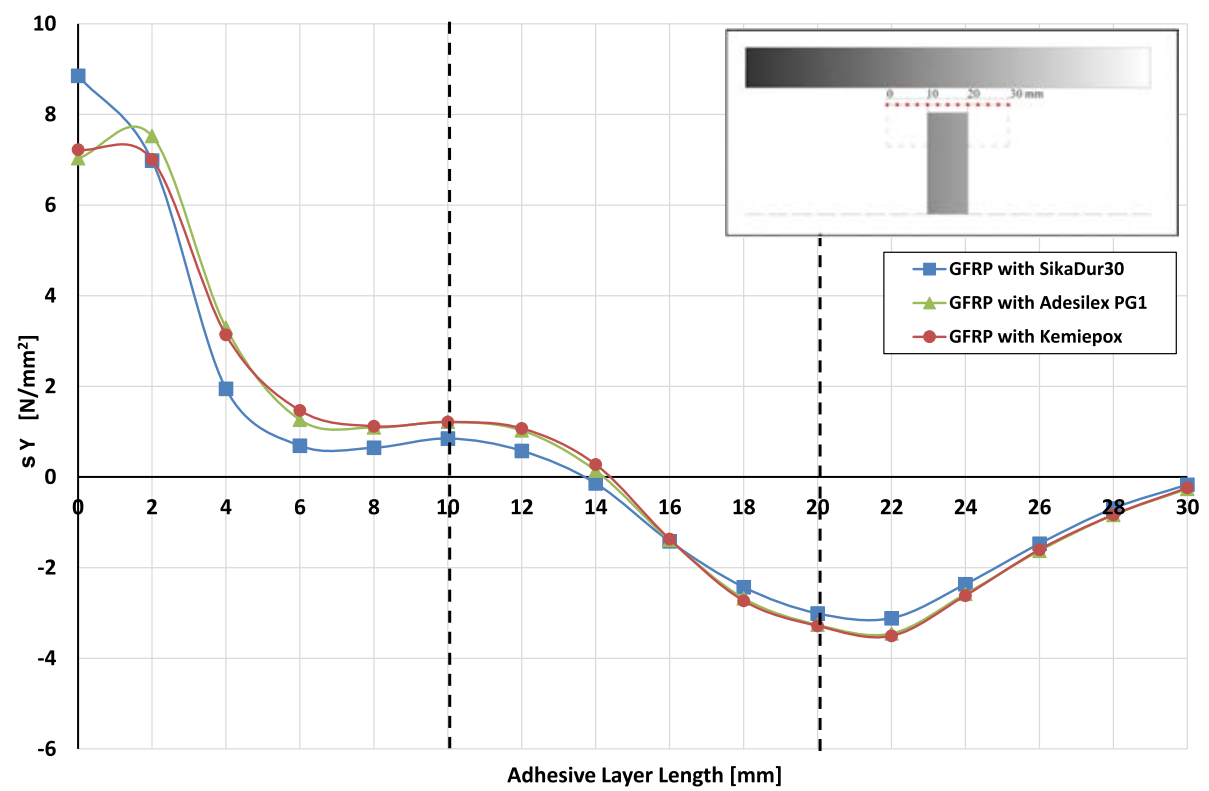

Fig. 13. Stress distribution $s_{y}$ relative to square reinforcement made of GFRP and adhesive layers made of different epoxy resins.
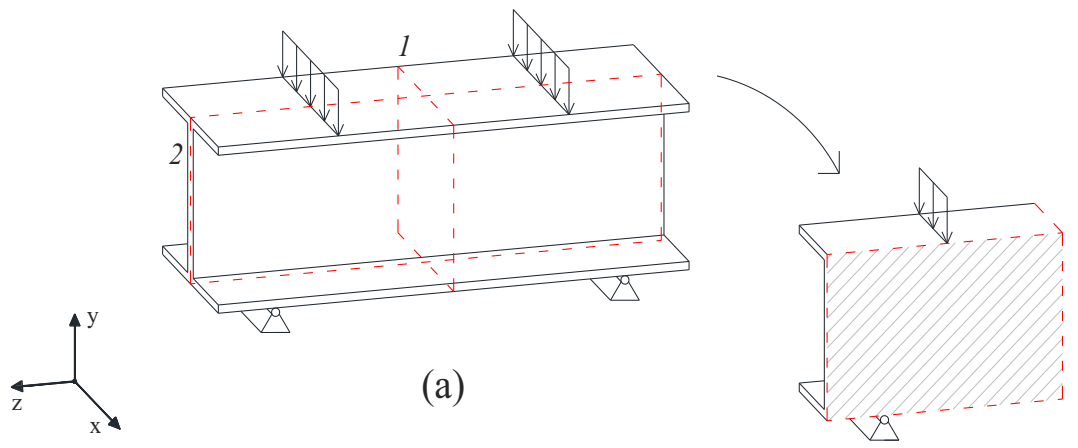

(b)

Fig. 14. Symmetry planes. 


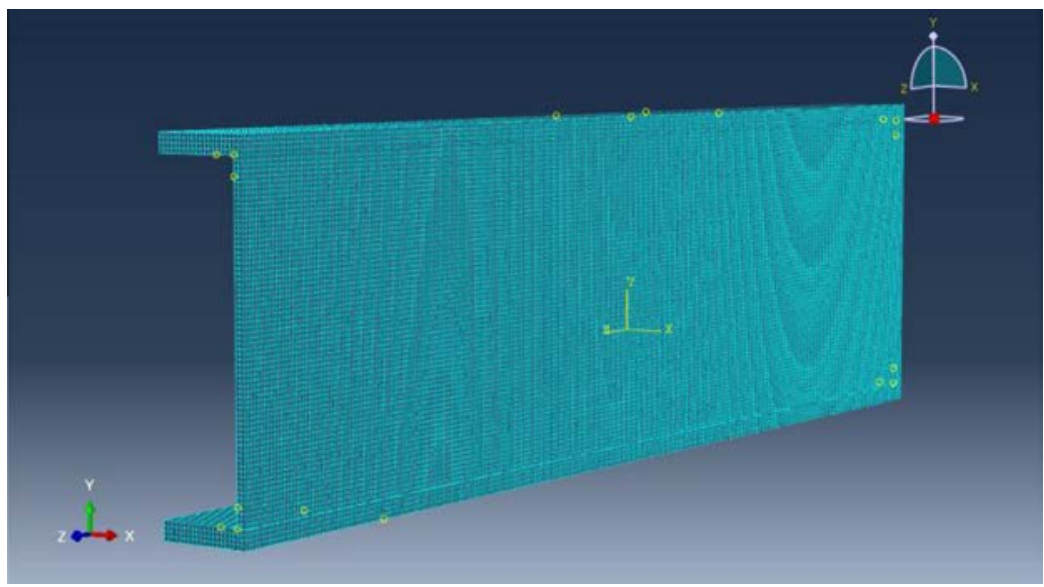

Fig. 15. 3D view mesh - Abaqus FEM model.

Table 5

3D-model mesh detail.

\begin{tabular}{llll}
\hline \multirow{2}{*}{ Mode I } & \multicolumn{4}{l}{ Number of finite elements } \\
\cline { 2 - 4 } & Upper flange & Lower flange & Web \\
\hline 1 & 22,400 & 22,400 & 20,834 \\
\hline
\end{tabular}

Table 6

3D-model mesh detail.

\begin{tabular}{ll}
\hline Reinforcement & Number of finite elements \\
\hline Square $10 \times 10$ & 4,480 \\
Square $15 \times 15$ & 10,080 \\
Rectangle $10 \times 20$ & 8,960 \\
Rectangle $20 \times 10$ & 8,960 \\
Triangle $10 \times 10$ & 2,240 \\
Triangle $15 \times 15$ & 5,040 \\
Pluris rectangle $10 \times 10$ & 3,360 \\
Pluris rectangle $15 \times 20$ & 11,828 \\
\hline
\end{tabular}

the adhesive reinforcement (when made of epoxy resin) by means of ratio $E_{\text {adhesive }} / E_{G F R P}=n\left(E_{\text {adhesive }}=10400 \mathrm{MPa}\right)$.

Furthermore, the Young's Modulus, E, was evaluated in accordance with the European Standard UNI EN 13706-2 indications, considering the following two experimental points of coordinates $\left(v_{1}, P_{1}\right)$ and $\left(v_{2}, P_{2}\right)$ with $v_{1}=L / 500=2.36 \mathrm{~mm}$ and $v_{2}=L / 200=5.90 \mathrm{~mm}$. The final formula is:

$E=\alpha \frac{L^{3}}{I_{x}} \frac{\left(P_{2}-P_{1}\right)}{\left(v_{2}-v_{1}\right)}$ with $\alpha \approx \frac{15}{384}$

In Eq. (1), $P_{1}=P_{1}\left(v_{1}\right)$ and $P_{2}=P_{2}\left(v_{2}\right)$ are the loads corresponding to the flexural mid-span deflections $v_{1}$ and $v_{2}$, respectively; the symbol $I_{x}$ denotes the second moment of area of the profile. Coefficient $\alpha$ accounts for shear deformability according to the Timoshenko beam model and depends on the static scheme considered.

The results summarized in Table 7 allow us to make the following conclusions:

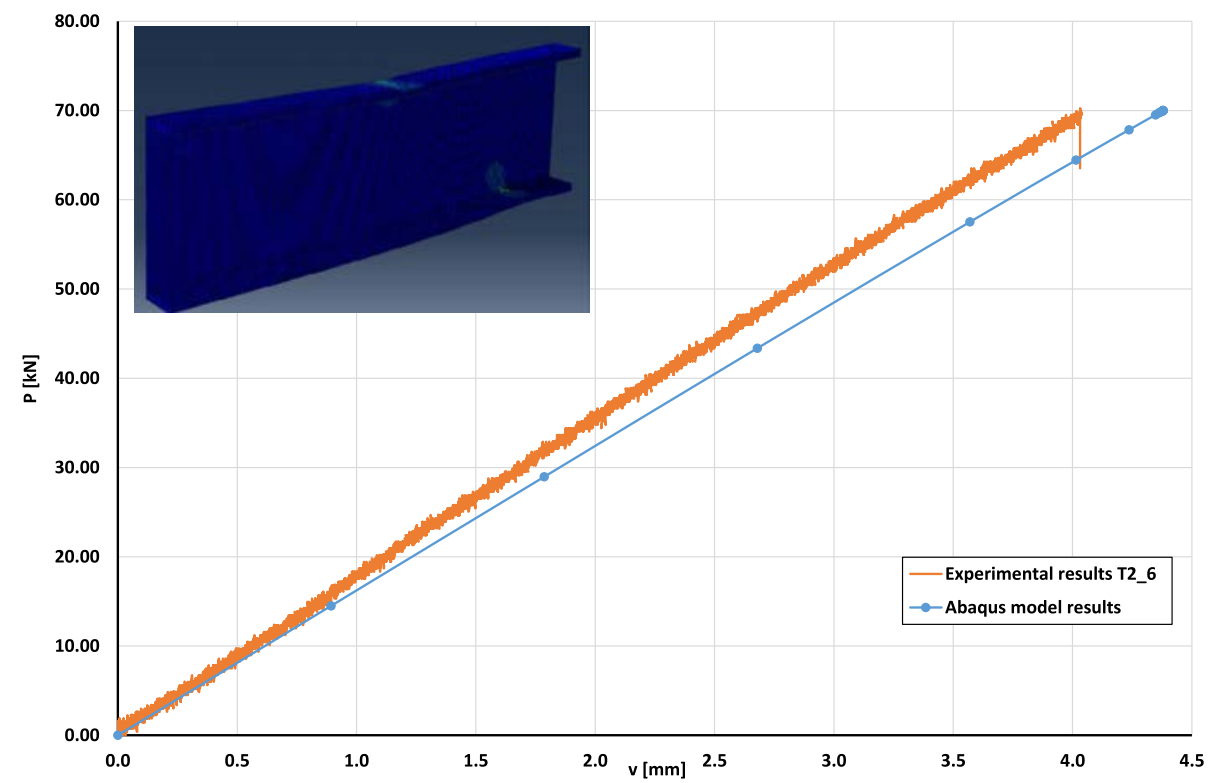

Fig. 16. Comparison between results of T2_6 beam and FE model. 


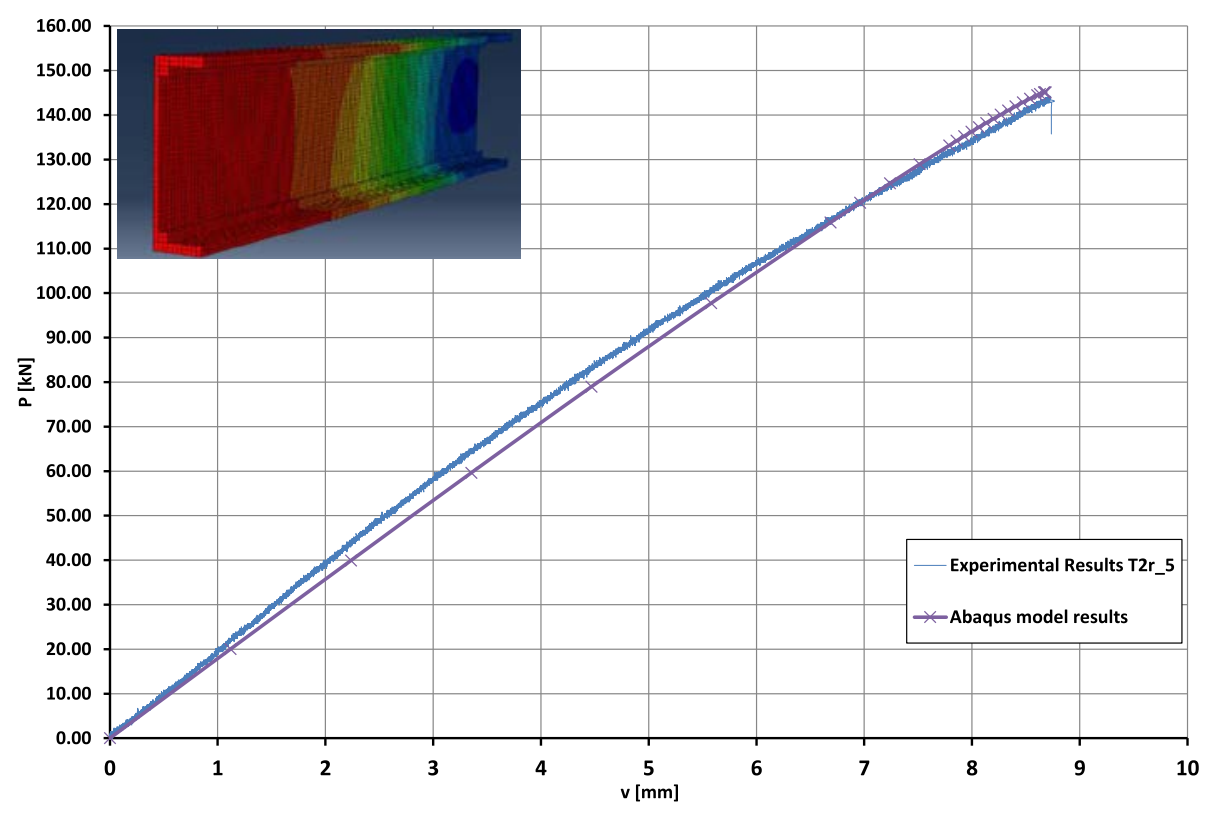

Fig. 17. Comparison between results of T2r_5 beams and FE model.

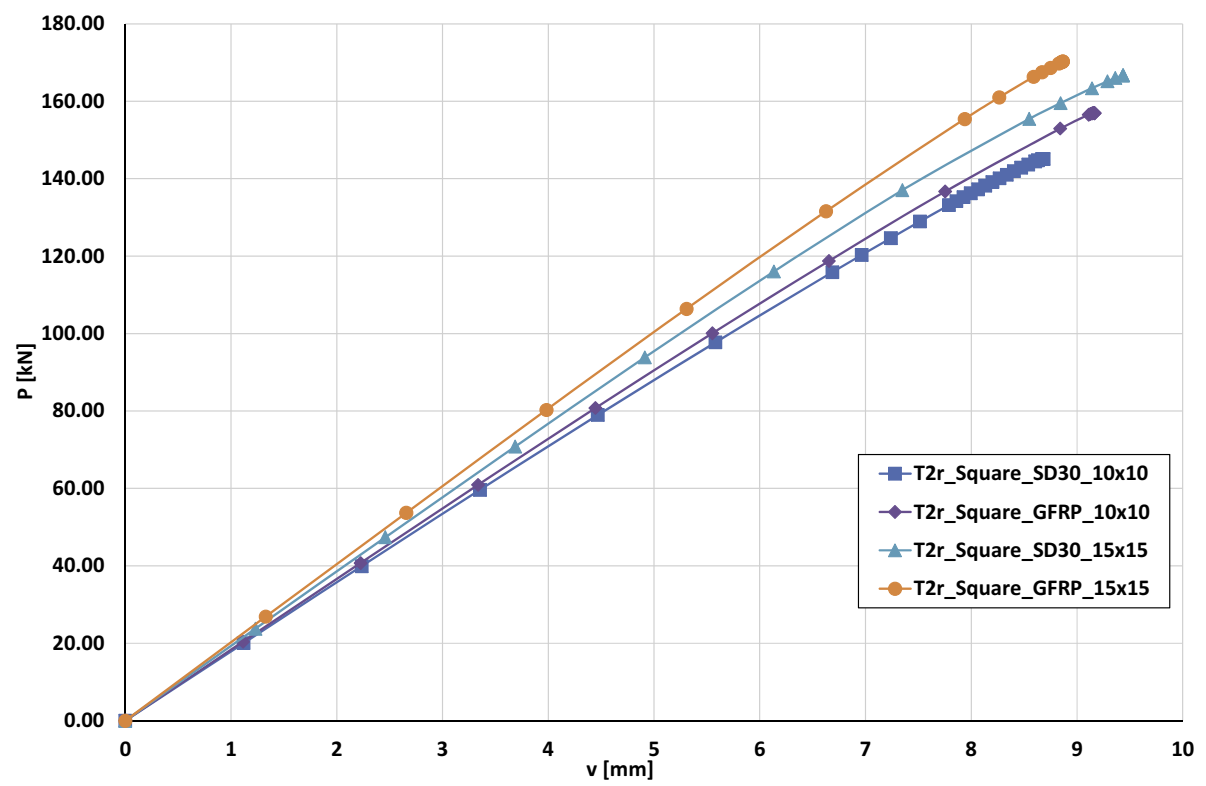

Fig. 18. Load vs. mid-span flexural deflection curve - (square reinforcement).

(1) The 3D numerical analyses confirm the 2D numerical results. In fact, for a fixed reinforcement geometry, the GFRP material gives a better mechanical response, in terms of failure load and flexural stiffness, than epoxy resin material.

(2) The maximum value of the flexural stiffness was obtained for the square and pluris rectangle reinforcements in GFRP (more or less $640,000 \mathrm{Nm}^{2}$ with respect to the mean value of $500,000 \mathrm{Nm}^{2}$ obtained experimentally).

(3) The maximum value of the failure load was obtained for the square and pluris rectangle reinforcements in GFRP: $170 \mathrm{kN}$ was obtained in case of square reinforcement and $186 \mathrm{kN}$ in case of pluris rectangle reinforcement respect to the mean value of $157 \mathrm{kN}$ obtained experimentally.
(4) The choice of the best reinforcement, in general, depends on the cost and manpower also. In fact, the square reinforcement presents more material than the pluris rectangle reinforcement $\left(200 \mathrm{~mm}^{2}\right.$ against $175 \mathrm{~mm}^{2}$ ) but the surface to bond is less for the square than for the pluris rectangle (30 mm against $35 \mathrm{~mm}$ ). The greater the surface to be bonded, the greater will be the risk of imperfections.

\section{Conclusions}

In this paper a wide numerical investigation has been developed in order to evaluate the mechanical response of bonded beams (obtained by bonding simple pultruded panels each other) 


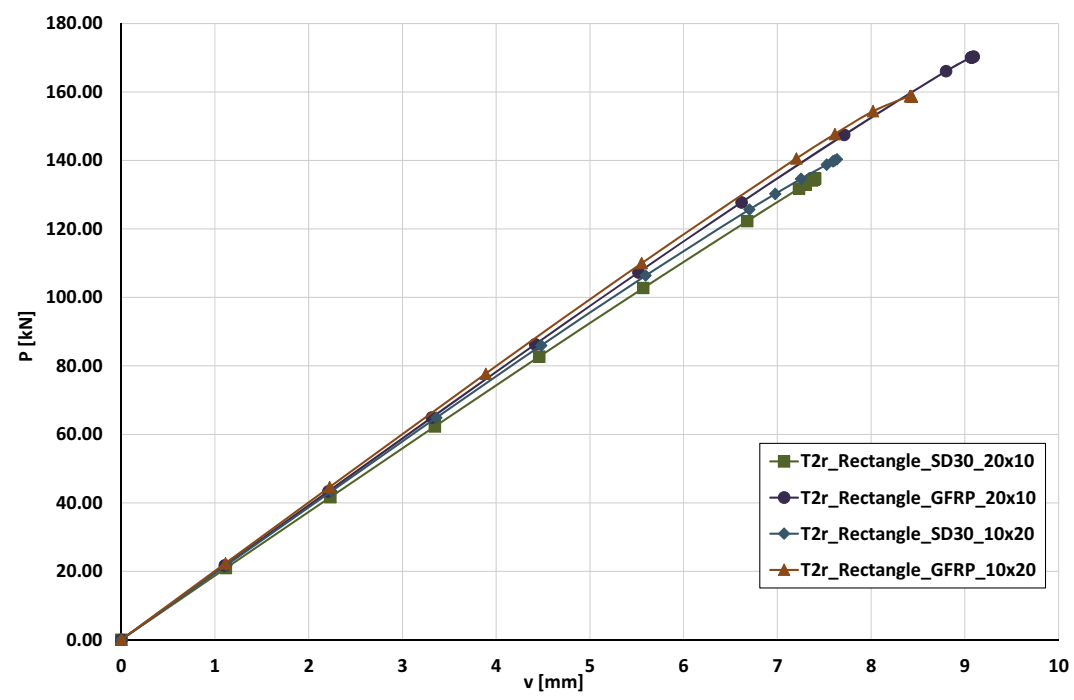

Fig. 19. Load vs. mid-span flexural deflection curve - (rectangle reinforcement).

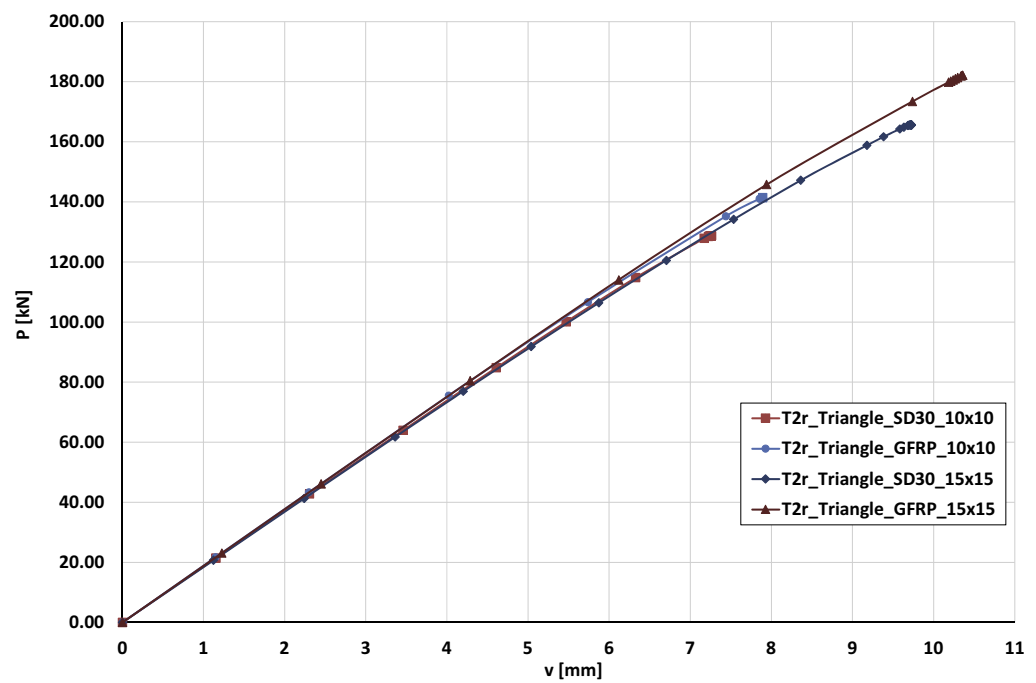

Fig. 20. Load vs. mid-span flexural deflection curve - (triangle reinforcement).

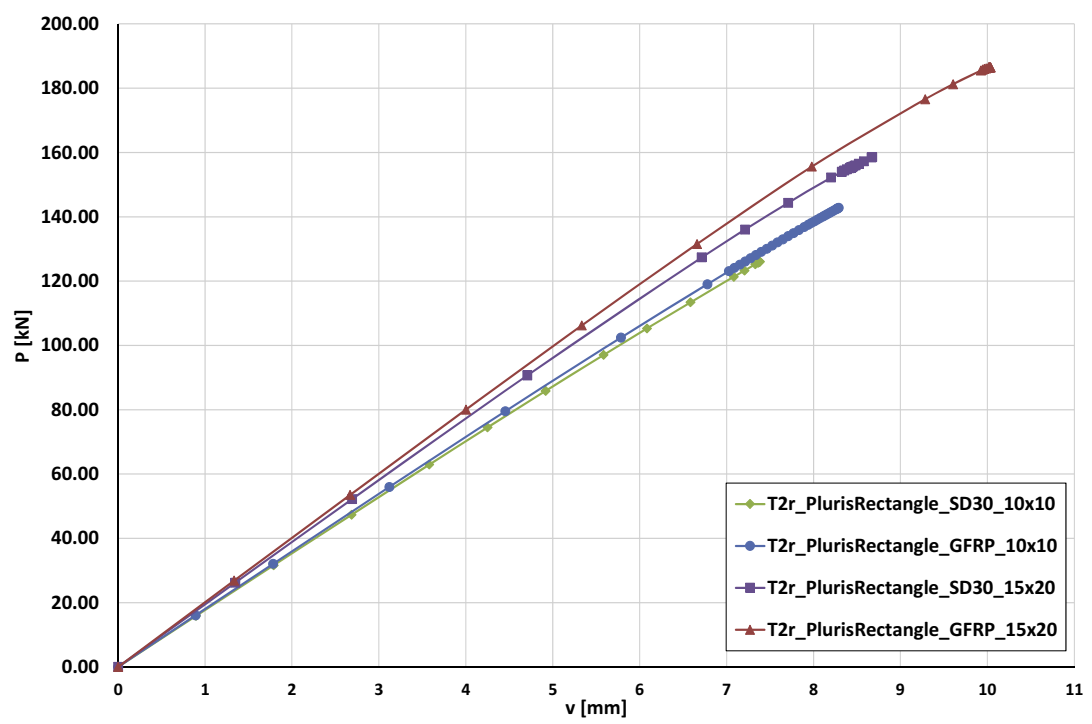

Fig. 21. Load vs. mid-span flexural deflection curve - (pluris rectangle reinforcement). 
Table 7

Flexural stiffness and failure load.

\begin{tabular}{|c|c|c|c|c|c|c|c|}
\hline \multicolumn{8}{|l|}{ Beam } \\
\hline Type & Area $\left[\mathrm{mm}^{2}\right]$ & Material & $E[\mathrm{MPa}]$ & $I_{x}\left[\mathrm{~mm}^{4}\right]$ & $E I_{x}\left[\mathrm{Nm}^{2}\right]$ & $P_{\max }[\mathrm{kN}]$ & $v[\mathrm{~mm}]$ \\
\hline \multirow[t]{4}{*}{ Square } & \multirow[t]{2}{*}{100.0} & SikaDur30 & 23,232 & $23,974,667$ & 556,977 & 145.11 & 8.69 \\
\hline & & GFRP & 22,279 & $25,793,333$ & 574,640 & 156.88 & 9.16 \\
\hline & \multirow[t]{2}{*}{225.0} & SikaDur30 & 23,893 & $25,181,500$ & 601,660 & 166.75 & 9.44 \\
\hline & & GFRP & 22,057 & $29,042,500$ & 640,596 & 170.31 & 8.86 \\
\hline \multirow[t]{4}{*}{ Rectangle } & \multirow[t]{2}{*}{200.0} & SikaDur30 & 23,528 & $25,049,333$ & 589,359 & 134.73 & 7.40 \\
\hline & & GFRP & 21,700 & $28,686,667$ & 622,488 & 170.40 & 9.11 \\
\hline & \multirow[t]{2}{*}{200.0} & SikaDur30 & 24,401 & $24,811,619$ & 605,437 & 140.52 & 7.68 \\
\hline & & GFRP & 22,587 & $28,046,667$ & 633,503 & 158.83 & 8.44 \\
\hline \multirow[t]{4}{*}{ Triangle } & \multirow[t]{2}{*}{50.0} & SikaDur30 & 24,867 & $23,458,381$ & 583,333 & 128.68 & 7.26 \\
\hline & & GFRP & 24,292 & $24,403,333$ & 592,801 & 141.29 & 7.89 \\
\hline & \multirow[t]{2}{*}{112.5} & SikaDur30 & 23,959 & $24,109,696$ & 577,647 & 165.66 & 9.73 \\
\hline & & GFRP & 22,791 & $26,156,875$ & 596,152 & 182.17 & 10.36 \\
\hline \multirow[t]{4}{*}{ Pluris Rectangle } & \multirow[t]{2}{*}{75.0} & SikaDur30 & 23,276 & $23,721,786$ & 552,143 & 126.09 & 7.38 \\
\hline & & GFRP & 22,378 & $25,112,500$ & 561,960 & 142.80 & 8.29 \\
\hline & \multirow[t]{2}{*}{174.0} & SikaDur30 & 24,473 & $24,774,270$ & 614,570 & 158.58 & 8.67 \\
\hline & & GFRP & 22,780 & $27,946,112$ & 636,608 & 186.44 & 10.04 \\
\hline
\end{tabular}

when a reinforcement at the web-flange junction was considered. Within this framework, the Abaqus FEA code was used.

In particular, the numerical investigation consisted of two different models: a 2D model and a 3D model.

The 2D-model was used to study the stress distribution in the adhesive layer when different types (varying the geometry) of reinforcement were used.

The 3D-model was implemented in order to study the influence of such different reinforcements on the mechanical response of bonded beams in terms of failure load and flexural stiffness making a comparison with the experimental results.

The numerical results have shown how it is possible to obtain, for these new bonded beams, levels of performance higher than those of the current pultruded beams. In detail, increments of $20 \%$ and $12 \%$ were reached with respect to failure load and flexural stiffness, respectively.

The numerical results obtained in this work represent the basis for the future experimental campaign in which the role of the web/ flange reinforcement, here numerically investigated, will be tested. Furthermore, complex cross-sectional shapes will be studied experimentally as well as numerically by using the approach discussed in this paper.

\section{Acknowledgements}

The Italian Department of Civil Protection (DPC - project ReLuis 2015) and the University of Salerno (project Farb 2014 - coordinated by Francesco Ascione) provided financial support to this research.

\section{References}

[1] Hollaway LC. Applications of fibre-reinforced polymer composite materials. In: ICE manual of construction materials: polymers and polymer fibre composites. London: Thomas Telford Limited; 2010. p. 109-27.

[2] Bank LC. Composites for construction-structural design with FRP materials. New Jersey: John Wiley \& Sons; 2006.

[3] Halliwell SM. Polymer composites in construction, BRE/DETR UK, BR405. UK: Building Research Establishment; 2000.

[4] Eurocomp design code and handbook. Structural design of polymer composites. The European Structural Polymeric Composites Group; 1996 (ISBN 0419194509).

[5] European Committee for Standardization (CEN). EN 13706: reinforced plastics composites-specification for pultruded profiles. Part 1: designation; part 2: methods of test and general requirements; part 3: specific requirements. Brussels: CEN; 2002.

[6] Technical Document CNR-DT 205/2007. Guide for the design and construction of structures made of FRP pultruded elements. Rome: Italian National Research Council (CNR); 2008.

[7] Chataigner S, Caron JF, Diaz A, Aubagnac C, Benzarti K. Non-linear failure criteria for a double lap bonded joint. Int J Adhes Adhes 2010;30:10-20.

[8] Cognard JY, Devaux H, Sohier L. Numerical analysis and optimization of cylindrical adhesive joints under tensile loads. Int J Adhes Adhes 2010;30:706-19.

[9] Freddi F, Sacco E. Mortar joints influence in debonding of masonry element strengthened with FRP. Key Eng Mater 2015;624:197-204.

[10] Carrara P. Freddi F. Statistical assessment of a design formula for the debonding resistance of FRP reinforcements externally glued on masonry units. Composites B 2014;66:65-82.

[11] D’Aniello M, Portioli F, Landolfo R. Lap shear tests on hot-driven steel riveted connections strengthened by means of C-FRPS. Composites B 2014;59C:140-52.

[12] Ascione F. Adhesive lap-joints: a micro-scale numerical investigation. Mech Res Commun 2010;37:169-72.

[13] Ascione F. A preliminary numerical and experimental investigation on the shear stress distribution on multi-row bolted FRP joints. Mech Res Commun 2010;37:164-8.

[14] Ascione F, Mancusi G, Spadea S, Lamberti M, Lebon F, Maurel-Pantel A. On the flexural behavior of GFRP beams obtained by bonding simple panels: an experimental investigation. Compos Struct 2015;131:55-65. 